\title{
Effect of Resistance Training in the Treatment of Pre-Sarcopenia or Sarcopenia and Pre-Frailty or Frailty in Older People: A Systematic Review and Meta-Analysis of Randomized Controlled Studies
}

Karolina Talar ( $\boldsymbol{\sim}$ karotalar@gmail.com )

Akademia Wychowania Fizycznego im Bronislawa Czecha https://orcid.org/0000-0001-5945-2130

Tomas Vetrovsky

Univerzita Karlova Fakulta telesne vychovy a sportu

Ewa Kalamacka

Akademia Wychowania Fizycznego im Bronislawa Czecha

Michal Steffl

Univerzita Karlova Fakulta telesne vychovy a sportu

Research article

Keywords: Effect of Resistance Training, Treatment of Pre-Sarcopenia

Posted Date: October 18th, 2019

DOI: https://doi.org/10.21203/rs.2.16189/v1

License: (c) (i) This work is licensed under a Creative Commons Attribution 4.0 International License.

Read Full License 


\section{Abstract}

Background: Resistance training (RT) is considered as an effective method to increase muscle strength and physical performance in elderly people.

Methods: A search from the earliest record up to and including June 2019 was carried out using the following electronic databases: PubMed, Scopus and Web of Science. The search strategy employed combined the terms related to the population (e.g. 'sarcopenia', 'frailty') with terms for the intervention (e.g. 'resistance training', 'strength training').

Results: 11 studies including 2691 subjects were included in our meta-analysis (aged 64-98). Training duration ranged from 8 to 48 weeks and intensity up to $80 \%$ of 1-RM. According to the meta-analyses, RT had statistically significant effect on all the measures except handgrip strength. In handgrip strength Effect size (ES) was 0.58 (95\% Cl: -0.10 to 1.26$) \mathrm{p}=0.076$ with the moderate heterogeneity (I $2=58.6 \%$ ). ES in legs strength was $0.52(95 \% \mathrm{Cl} 0.11$ to 0.92$) \mathrm{p}=0.022, \mathrm{I} 2=42.0 \%$. The biggest ES was in TUG test where ES was $0.90(95 \% \mathrm{Cl} 0.19$ to 1.60$) \mathrm{p}=0.022$, however, there was a high heterogeneity I $2=89.6$. The high ES was found also in FFM $0.69(95 \% \mathrm{Cl} 0.17$ to 1.20) $\mathrm{p}=0.025$, and gait speed $0.41(95 \% \mathrm{Cl}$ 0.11 to 0.72$) p=0.017$. In both cases, there was small heterogeneity I $2=13.2 \%$ respective $38.3 \%$. The overall ES was estimated $0.67(95 \% \mathrm{Cl} 0.40$ to 0.93$) \mathrm{p}<0.001$. Nevertheless, the heterogeneity was high I $2=78.1 \%$.

Conclusion: RT interventions in pre-frail, frail, pre-sarcopenic and sarcopenic older adults, provided evidence that RT has positive effects on most of the outcome measurements included in the current revision except handgrip strength.

\section{Background}

Human ageing results in variety of changes to skeletal muscle. The term 'sarcopenia' was for the first time defined by Rosenberg et. al. in 1989 to indicate the loss of muscle mass that accompanies aging, derived from Greek as 'sarx' standing for flesh and 'penia' standing for loss [1]. This syndrome is characterized by degenerative loss of skeletal muscle mass and strength with a risk of physical disability, poor quality of life and death [2,3]. The European Working Group on Sarcopenia in Older People (EWGSOP) suggests the use of low muscle mass and low muscle function (strength or performance) in order to accurately diagnose sarcopenia while to identify pre-sarcopenia EWGSOP recommends the use of low muscle mass without influence on physical performance or muscle strength [4].

Frailty is an age-associated medical syndrome that embodies high risk for falls, disability, hospitalization, and mortality among older adults [5-8]. The phenomenon of prevalence of frailty in people older than 65 years is high, increases with age $[5,6,9]$ and may lead to disability $[10,11]$. The diagnosis of frailty comprises three or more indicators, including physical impairments (e.g., low gait speed, fatigue, and low grip strength), weight loss, and low physical activity, whereas the presence of pre-frailty defines one or two indicators $[6,12]$. 
Definitions of both sarcopenia and frailty are still developing, both concepts distinctly overlap in their physical aspects due to their close relationship with the aging process [13]. However, assessing framework within which sarcopenia and frailty can be accommodated and studied is enormously difficult, because frailty and sarcopenia are the "two sides of the same coin" [14,15].

Previous studies showed that resistance training (RT) may weaken skeletal muscle function deficits in older adults [16]. Resistance training studies have consistently demonstrated significant increases in lean weight and metabolic rate, as well as significant decreases in fat weight, beginning with the progressive reduction in muscle mass and resting metabolism associated with inactive aging, [17]. Thus it seems understandable that in order to improve muscle strength and physical performance in elderly people RT was considered as an effective method of treatment against pre-sarcopenia, sarcopenia, pre-frailty and frailty [18-21].

The purpose of this review was to use systematic review and meta-analytical approaches to examine the effect of RT in the treatment of pre-sarcopenia or sarcopenia and pre-frailty or frailty in older people.

\section{Methods}

\subsection{Search Strategy}

A search from the earliest record up to and including June 2019 was carried out using the following electronic databases: PubMed, Scopus and Web of Science. The search strategy employed combined the terms related to the population (e.g. sarcopenia, frailty) with terms for the intervention (e.g. resistance training, strength training). The titles and abstracts of the retrieved articles were individually evaluated to assess the eligibility of studies to be included in the review and meta-analysis. The reviewers were not blinded to the studies' authors, institutions or journals of publication. Studies with abstracts that did not provide sufficient information according to the inclusion criteria were retrieved for full text evaluation. The authors registered systematic review in PROSPERO, International prospective register of systematic reviews (ref: CRD42019138253) and conducted meta-analysis and systematic review in pursuance of the PRISMA Statement (Preferred Reporting Items for Systematic Reviews and Meta-Analyses) [22].

\subsection{Inclusion Criteria}

The following inclusion criteria have been applied: (1) research papers released only in English; (2) conference materials, theses, doctoral dissertations and monographs were eliminated; (3) TUG, FFM, HGS, lower limbs strength and gait speed tests were taken into account; (4) RT intervention; (5) older persons (starting at 64 years old); (6) symptoms of pre-frailty, frailty, pre-sarcopenia or sarcopenia must have been diagnosed; (7) measured dynamic changes in muscle strength; and (8) 8 weeks duration.

\subsection{Data Extraction}


The authors (KT and MS) extracted independently following variables: (1) descriptive data, including the same sample size, age and RT experience; (2) characteristics of the RT training, including training frequency, trial length, number of sets and number of repetitions per set; (3) muscular strength tests used; and (4) the outcomes referred to muscle strength. Any discrepancies were cross-checked and discussed between the authors.

\subsection{Methodological Quality}

The Downs and Black checklist was used to assess the quality of the methodology [23]. Studies were rated on a scale from "poor quality" ( 11 points) to "good quality" (20-29 points), as in Hacket et. al. [24] and Grgic et al. [25]. Two reviewers (KT and MS) were independently rating these studies. If there are any disputes related to the quality assessment of the research, the third reviewer (EK) helped in obtaining consent.

\subsection{Statistical Analysis}

The effect sizes (ES) were determined as the standardized mean differences between the resistance training group and the control group. Random-effects meta-analysis was performed using robust variance estimation (RVE) with small-sample corrections which allows for the inclusion of multiple effect sizes from one study, even in the absence of information on the covariance of these effect sizes $[26,27]$. The RVE method requires a user to specify a value of within-study effect size correlation with the default value of 0.8 . A sensitivity analysis that used alternative correlational values found that their choice does not impact the overall results of the meta-analysis. Statistical heterogeneity between trials was examined using the $\mathrm{I}^{2}$ statistics, with values of $\mathrm{I}^{2}$ more than $25 \%, 50 \%$, and $75 \%$ reflecting low, moderate, and high heterogeneity, respectively. All analyses were conducted using packages robumeta (version 2.0) and metafor (version 2.0-0) in R version 3.4.4 (The R Foundation for Statistical Computing, Vienna, Austria).

\section{Results}

\subsection{Study Selection}

During the search of the databases the authors have found 490 results, among which 39 studies met the inclusion criteria. Further tracking of the citations of the research via other sources resulted in another 122 search results. The authors also took into account the reference lists. However, they did not find relevant results; for this reason, the overall number of studies comprising of meta-analysis is 11 and the review is 16. The search stages and study selection process are showed in Figure 1.

\subsection{Study Characterictics}


The mean duration of RT programs was approximately 22 weeks (range 8-48 weeks) and the most common comparison of RT frequency was 2-3 times per week of training sessions (in 14 studies). Table 1 summarizes the studies analyzed and Table 2 shows related outcomes evaluated in the studies.

\subsection{Meta-analyses}

According to the meta-analyses, RT had statistically significant effect on all the measures except handgrip strength. In handgrip strength effect size (ES) was $0.58(95 \% \mathrm{Cl}:-0.10$ to 1.26$) \mathrm{p}=0.076$ (Figure 2) with the moderate heterogeneity $\left(I^{2}=58.6 \%\right)$. ES in legs strength was $0.52(95 \% \mathrm{Cl} 0.11$ to $0.92) p=0.022, l^{2}=42.0 \%$ (Figure 3). The biggest ES was in TUG test where ES was $0.90(95 \% \mathrm{Cl} 0.19$ to 1.60) $p=0.022$, however, there was a high heterogeneity $\left.\right|^{2}=89.6$ (Figure 4). The high ES was found also in FFM 0.69 ( $95 \% \mathrm{Cl} 0.17$ to 1.20$) \mathrm{p}=0.025$, and gait speed 0.41 (95\% $\mathrm{Cl} 0.11$ to 0.72$) \mathrm{p}=0.017$. In both cases, there was small heterogeneity $\mathrm{I}^{2}=13.2 \%$ respective $38.3 \%$ (Figures 5 and 6 ). The overall ES was estimated 0.67 (95\% Cl 0.40 to 0.93 ) p 0.001 (Figure 7). Nevertheless, the heterogeneity was high $\mathrm{I}^{2}=$ $78.1 \%$.

\section{Discussion}

This systematic review and meta-analysis, which aimed to retrieve recent evidence examined the role of RT interventions in pre-frail, frail, sarcopenic and pre-sarcopenic older adults, provided evidence that RT has positive effects on most of the outcome measurements included in the current revision.

There is an emerging body of evidence showing that RT appears to be as effective as aerobic exercise training in reducing risk of several chronic diseases including sarcopenia [28]. The regular RT could effectively disturb processes that contribute to the progression of aging as it pertains to the mitochondrial theory [29]. Previous similar studies are in concordance with our findings. For example, a meta-analysis focusing a protein supplementation with muscle strengthening exercise confirmed that RT significantly contributed to the efficacy of the intervention in terms of muscle strength and physical mobility in elderly patients with a high risk of sarcopenia or frailty [30]. According to another metaanalysis, RT was found as effective for improving strength among older adults, particularly with higher intensity training and may be considered a viable strategy to prevent generalized muscular weakness associated with aging [18].

This review was strengthened by the use of a systematic search, precise eligibility criteria and scrupulous data extraction and quality assessment procedures. A robust variance estimate meta-analytical approach was firstly used to overcome the concern that studies may have had small sample sizes that provide insufficient power to detect significant differences between the two training conditions.

\section{Despite the efforts of the authors, this work has several limitations that should be taken into account when interpreting the findings of}




\title{
this review.
}

Firstly, variables such as intensity (loading) varied significantly between studies (from 65 to $100 \%$ of 1RM). According to Schoenfeld et. al. high-load training is considered as a greater than $60 \%$ of 1-RM [31]. It is possible, however, that this affected the results.

Secondly, as authors mentioned earlier, several studies have corroborated the effects of protein supplementation and RT [30]. However, creating a greater effect by combining these two is still seen as contentious issue [32].

\section{Lastly, we did not search studies published in non-English journals, what could have contributed to omission of relevant studies.}

\section{Conclusion}

RT interventions in pre-frail, frail, sarcopenic and pre-sarcopenic older adults, provided evidence that RT has positive effects on most of the outcome measurements included in the current revision except handgrip strength.

\section{Abbreviations}

EWGSOP: European Working Group on Sarcopenia in Older People

\author{
HGS: Handgrip strength
}

RCT: Randomized controlled trial

SRMA: Systematic review and meta-analysis

IWGS: International Working Group on Sarcopenia

PRISMA: Preferred Reporting Items for Systematic Reviews and Meta-Analyses

\section{Declarations}

\section{Acknowledgements}




\title{
Non applicable.
}

\section{Funding}

This meta-analysis was supported by the research grants of Charles University, Czech Republic (PRIMUS/19/HUM/012 and the project Q41). The funding agency played no role in study design, data collection and analysis, decision to publish, or preparation of the manuscript.

\section{Availability of data and materials}

\section{All data generated or analyzed during this study are included in this published article.}

\section{Author information}

\section{Authors' contributions}

$K T, T V$ and MS were primarily involved in conception and design of the study. KT, TV, EK and MS were responsible for acquisition of data, analysis and interpretation of data, KT, TV, EK and MS have been involved in drafting the manuscript, all authors had revised it critically and gave final approval of the version to be published.

\section{Ethics declarations}

\section{Ethics approval and consent to participate}

\author{
Not applicable.
}

\section{Consent for publication}

\author{
Not applicable.
}

\section{Competing interest}




\section{The authors declare that they have no competing interests.}

\section{References}

1. Rosenberg, I. H. Sarcopenia: Origins and Clinical Relevance. J. Nutr. 1997, 127, 990S-991S.

2. Delmonico, M. J.; Harris, T. B.; Lee, J.-S.; Visser, M.; Nevitt, M.; Kritchevsky, S. B.; Tylavsky, F. A.; Newman, A. B.; for the Health, Aging and Body Composition Study Alternative Definitions of Sarcopenia, Lower Extremity Performance, and Functional Impairment with Aging in Older Men and Women: SARCOPENIA INDICES, PERFORMANCE, AND AGING. J. Am. Geriatr. Soc. 2007, 55, 769774.

3. Goodpaster, B. H.; Park, S. W.; Harris, T. B.; Kritchevsky, S. B.; Nevitt, M.; Schwartz, A. V.; Simonsick, E. M.; Tylavsky, F. A.; Visser, M.; Newman, A. B.; et al. The Loss of Skeletal Muscle Strength, Mass, and Quality in Older Adults: The Health, Aging and Body Composition Study. J. Gerontol. A. Biol. Sci. Med. Sci. 2006, 61, 1059-1064.

4. Cruz-Jentoft, A. J.; Baeyens, J. P.; Bauer, J. M.; Boirie, Y.; Cederholm, T.; Landi, F.; Martin, F. C.; Michel, J.-P.; Rolland, Y.; Schneider, S. M.; et al. Sarcopenia: European consensus on definition and diagnosis: Report of the European Working Group on Sarcopenia in Older People. Age Ageing 2010, 39, 412423.

5. Bandeen-Roche, K.; Xue, Q.-L.; Ferrucci, L.; Walston, J.; Guralnik, J. M.; Chaves, P.; Zeger, S. L.; Fried, L. P. Phenotype of Frailty: Characterization in the Women's Health and Aging Studies. J. Gerontol. A. Biol. Sci. Med. Sci. 2006, 61, 262-266.

6. Fried, L. P.; Tangen, C. M.; Walston, J.; Newman, A. B.; Hirsch, C.; Gottdiener, J.; Seeman, T.; Tracy, R.; Kop, W. J.; Burke, G.; et al. Frailty in older adults: evidence for a phenotype. J. Gerontol. A. Biol. Sci. Med. Sci. 2001, 56, M146-156.

7. Graham, J. E.; Snih, S. A.; Berges, I. M.; Ray, L. A.; Markides, K. S.; Ottenbacher, K. J. Frailty and 10Year Mortality in Community-Living Mexican American Older Adults. Gerontology 2009, 55, 644-651.

8. Ensrud, K. E.; Ewing, S. K.; Cawthon, P.M.; Fink, H. A.; Taylor, B.C.; Cauley, J. A.; Dam, T.-T.; Marshall, L. M.; Orwoll, E. S.; Cummings, S. R.; et al. A Comparison of Frailty Indexes for the Prediction of Falls, Disability, Fractures, and Mortality in Older Men: FRAILTY INDEXES, FALLS, DISABILITY, FRACTURES, AND MORTALITY. J. Am. Geriatr. Soc. 2009, 57, 492-498.

9. Garcia-Garcia, F. J.; Gutierrez Avila, G.; Alfaro-Acha, A.; Amor Andres, M. S.; De Los Angeles De La Torre Lanza, M.; Escribano Aparicio, M. V.; Humanes Aparicio, S.; Larrion Zugasti, J. L.; GomezSerranillo Reus, M.; Rodriguez-Artalejo, F.; et al. The prevalence of frailty syndrome in an older population from Spain. The Toledo Study for Healthy Aging. J. Nutr. Health Aging 2011, 15, 852856.

10. Xue, Q.-L. The Frailty Syndrome: Definition and Natural History. Clin. Geriatr. Med. 2011, 27, 1-15.

11. Casas Herrero, A.; Izquierdo, M. Ejercicio físico como intervención eficaz en el anciano frágil. An. Sist. Sanit. Navar. 2012, 35, 69-85. 
12. Hanlon, P.; Nicholl, B. I.; Jani, B. D.; Lee, D.; McQueenie, R.; Mair, F. S. Frailty and pre-frailty in middleaged and older adults and its association with multimorbidity and mortality: a prospective analysis of 493737 UK Biobank participants. Lancet Public Health 2018, 3, e323-e332.

13. Cruz-Jentoft, A. J.; Kiesswetter, E.; Drey, M.; Sieber, C. C. Nutrition, frailty, and sarcopenia. Aging Clin. Exp. Res. 2017, 29, 43-48.

14. Physical Therapist; Nikolaou, D. Sarcopenia and Frailty: exercise treating methodology. J. Frailty Sarcopenia Falls 2016, 01, 24-28.

15. Cesari, M.; Landi, F.; Vellas, B.; Bernabei, R.; Marzetti, E. Sarcopenia and Physical Frailty: Two Sides of the Same Coin. Front. Aging Neurosci. 2014, 6.

16. Papa, E. V.; Dong, X.; Hassan, M. Resistance training for activity limitations in older adults with skeletal muscle function deficits: a systematic review. Clin. Interv. Aging 2017, Volume 12, 955-961.

17. Westcott, W. L. Resistance Training is Medicine: Effects of Strength Training on Health. Curr. Sports Med. Rep. 2012, 11, 209-216.

18. Peterson, M. D.; Rhea, M. R.; Sen, A.; Gordon, P.M. Resistance exercise for muscular strength in older adults: A meta-analysis. Ageing Res. Rev. 2010, 9, 226-237.

19. Stewart, V. H.; Saunders, D. H.; Greig, C. A. Responsiveness of muscle size and strength to physical training in very elderly people: A systematic review: Hypertrophic ability of older muscle. Scand. J. Med. Sci. Sports 2014, 24, e1-e10.

20. Hazell, T.; Kenno, K.; Jakobi, J. Functional Benefit of Power Training for Older Adults. J. Aging Phys. Act. 2007, 15, 349-359.

21. Tschopp, M.; Sattelmayer, M. K.; Hilfiker, R. Is power training or conventional resistance training better for function in elderly persons? A meta-analysis. Age Ageing 2011, 40, 549-556.

22. Moher, D.; Liberati, A.; Tetzlaff, J.; Altman, D. G.; The PRISMA Group Preferred Reporting Items for Systematic Reviews and Meta-Analyses: The PRISMA Statement. PLoS Med. 2009, 6, e1000097.

23. Downs, S. H.; Black, N. The feasibility of creating a checklist for the assessment of the methodological quality both of randomised and non-randomised studies of health care interventions. J. Epidemiol. Community Health 1998, 52, 377-384.

24. Hackett, D. A.; Davies, T. B.; Orr, R.; Kuang, K.; Halaki, M. Effect of movement velocity during resistance training on muscle-specific hypertrophy: A systematic review. Eur. J. Sport Sci. 2018, 18, 473-482.

25. Grgic, J.; Schoenfeld, B. J.; Davies, T. B.; Lazinica, B.; Krieger, J. W.; Pedisic, Z. Effect of Resistance Training Frequency on Gains in Muscular Strength: A Systematic Review and Meta-Analysis. Sports Med. 2018, 48, 1207-1220.

26. Hedges, L. V.; Tipton, E.; Johnson, M. C. Robust variance estimation in meta-regression with dependent effect size estimates. Res. Synth. Methods 2010, 1, 39-65.

27. Tipton, E. Small sample adjustments for robust variance estimation with meta-regression. Psychol. Methods 2015, 20, 375-393. 
28. Mcleod, J. C.; Stokes, T.; Phillips, S. M. Resistance Exercise Training as a Primary Countermeasure to Age-Related Chronic Disease. Front. Physiol. 2019, 10, 645.

29. Johnston, A. P. W.; De Lisio, M.; Parise, G. Resistance training, sarcopenia, and the mitochondrial theory of aging. Appl. Physiol. Nutr. Metab. Physiol. Appl. Nutr. Metab. 2008, 33, 191-199.

30. Liao, C.-D.; Chen, H.-C.; Huang, S.-W.; Liou, T.-H. The Role of Muscle Mass Gain Following Protein Supplementation Plus Exercise Therapy in Older Adults with Sarcopenia and Frailty Risks: A Systematic Review and Meta-Regression Analysis of Randomized Trials. Nutrients 2019, 11.

31. Schoenfeld, B. J.; Grgic, J.; Ogborn, D.; Krieger, J. W. Strength and Hypertrophy Adaptations Between Low- vs. High-Load Resistance Training: A Systematic Review and Meta-analysis. J. Strength Cond. Res. 2017, 31, 3508-3523.

32. Hou, L.; Lei, Y.; Li, X.; Huo, C.; Jia, X.; Yang, J.; Xu, R.; Wang, X.-M. Effect of Protein Supplementation Combined With Resistance Training on Muscle Mass, Strength and Function in the Elderly: A Systematic Review and Meta-Analysis. J. Nutr. Health Aging 2019, 23, 451-458.

\section{Tables}

Due to technical limitations, tables are only available as a download in the supplemental files section

\section{Figures}




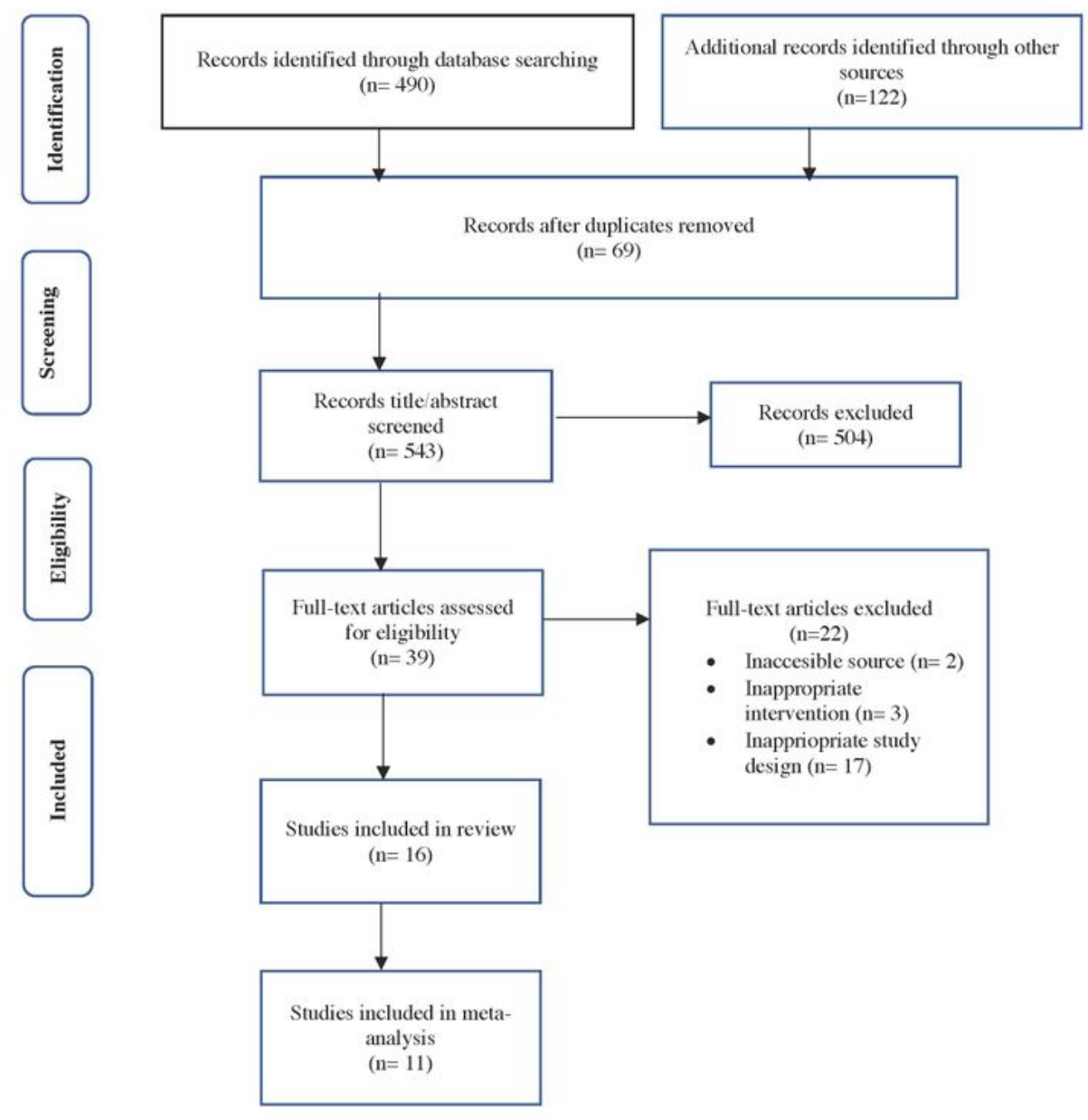

Figure 1 


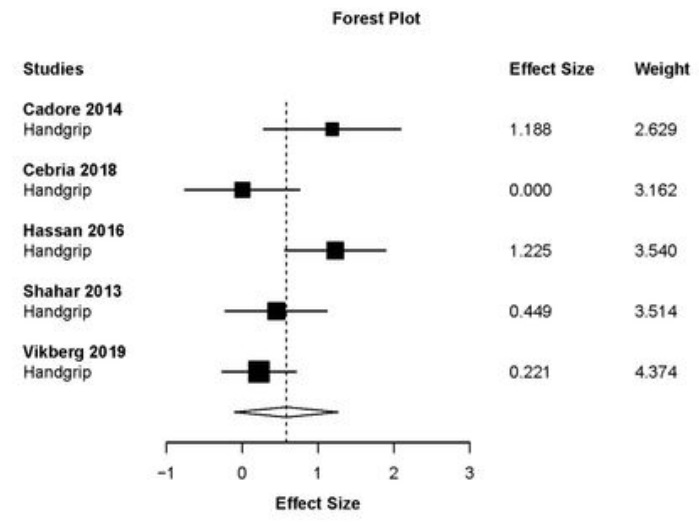

Figure 2

Page 12/18 
Forest Plot

$\begin{array}{llll}\text { Studies } & & \text { Effect Size } & \text { Weight } \\ \text { Binder 2005 } & & & 3.952 \\ \text { Knee extension isokinetic } \\ \text { Knee flexion isokinetic }\end{array}$

Figure 3 


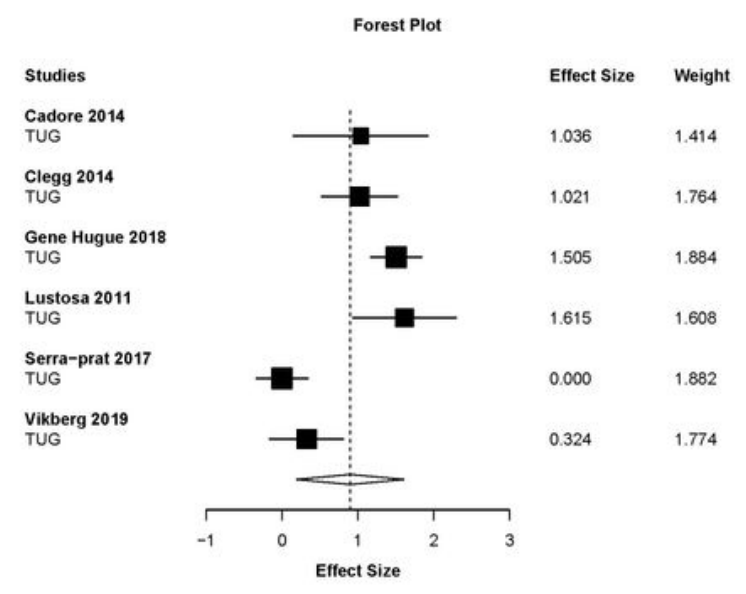

Figure 4 


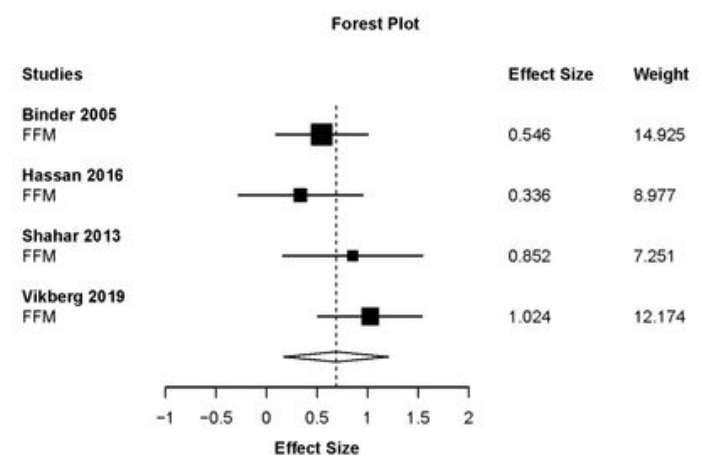

Figure 5

Page 15/18 


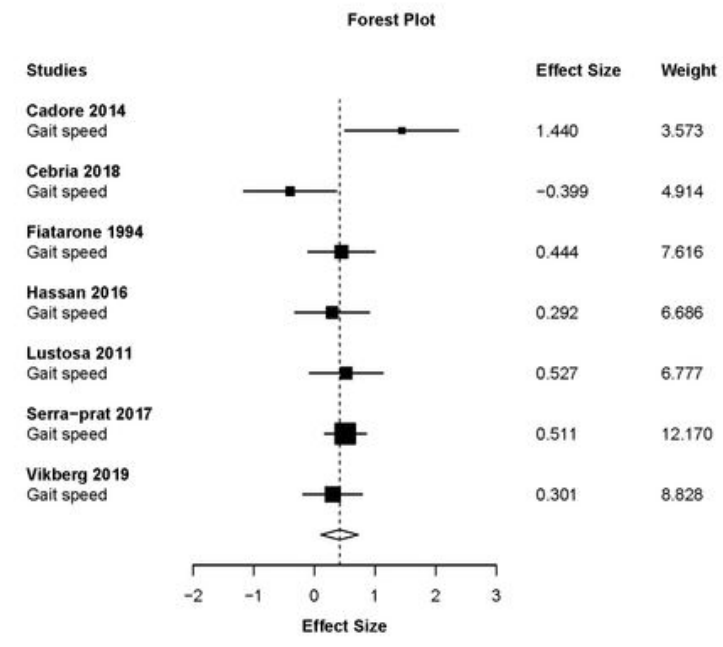

Figure 6 


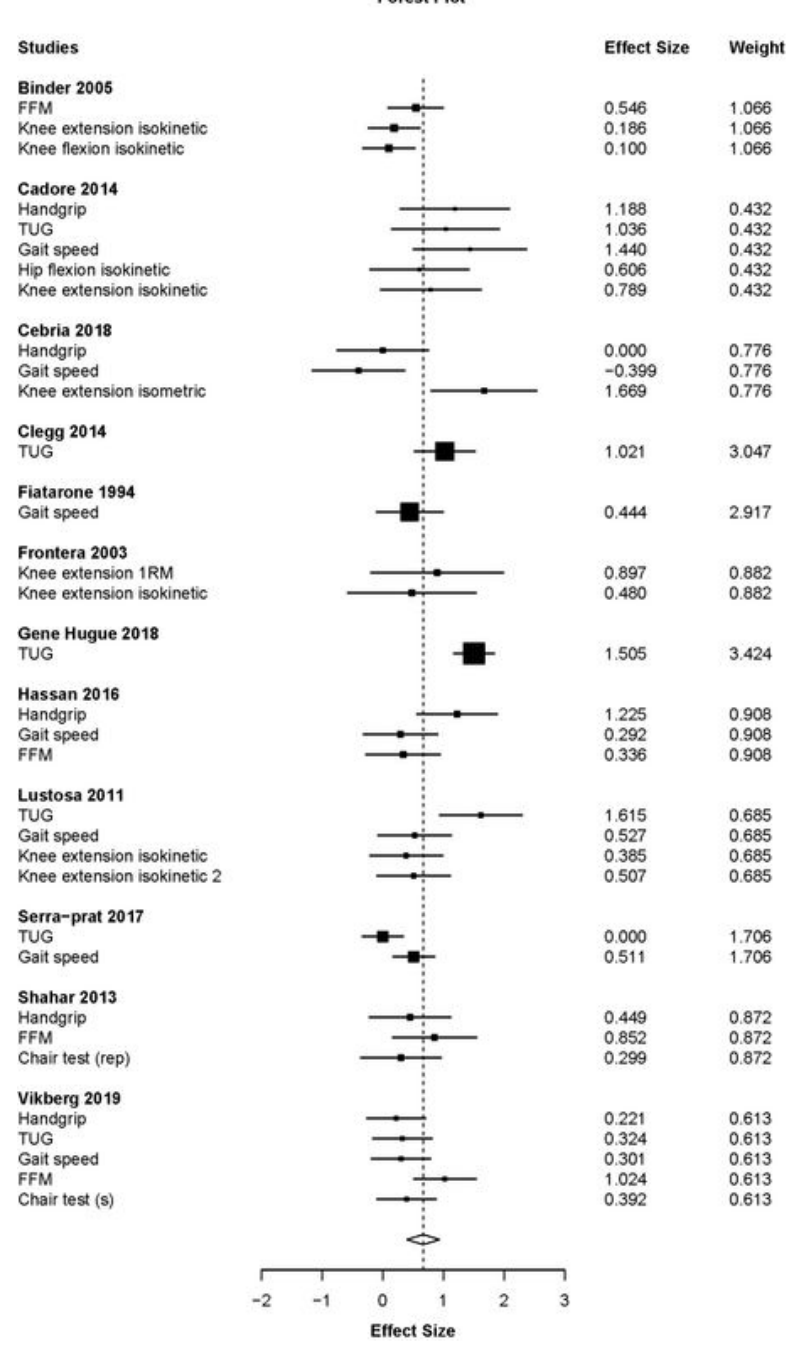

\section{Figure 7}

\section{Supplementary Files}

This is a list of supplementary files associated with this preprint. Click to download.

- Table2Mainresistancetraining2.pdf 
- PRISMA2009checklist.doc

- TableParticipantcharacteristicsofincludedstudies.pdf 